Andrew S.H. Chan MBBS DA FRCA FRCPC, Chidambaram Ananthanarayan MD FRCPC, Stephen H. Rolbin MDCM FRCPC

\title{
Alternating nitro- glycerin and syntocinon to facilitate uterine exploration and removal of an adherent placenta
}

Nitroglycerin (NTG) has been demonstrated to provide uterine relaxation in the management of various obstetric complications. A 32-yr-old woman presented $40 \mathrm{~min}$ postpartum for manual removal of a retained placenta. Repeated, alternating doses of NTG $250 \mu \mathrm{g}$ and syntocinon (SYN) $10 \mathrm{U}$ iv were used over 15 min to produce periods of uterine relaxation and contraction respectively for uterine exploration. Multiple attempts to extract the placenta failed and a diagnosis of placenta accreta was made. There were no major side effects from this combination of drugs apart from a transient $20 \%$ decrease in blood pressure afier NTG, which responded to ephedrine 10-15 mg $i v$. The rapid change in uterine tone was believed to be due not only to the short duration of action of NTG and SYN, but also to the possible physiological antagonism between the two drugs. The mechanism of interaction may involve calcium mobilization and myosin light chain phosphorylation. We conclude that NTG and SYN can be used to produce alternating periods of uterine relaxation and contraction rapidly and consistently with little sustained effects from either agents.

Il a déjà été démontré que la nitroglycérine (NTG) produisait une relaxation utérine favorable au traitement de plusieurs complications obstétricales. Une femme de 32 ans se présente pour extraction manuelle du placenta 40 min après l'accouchement. Des doses répétées de NTG $250 \mu \mathrm{g}$ et de syntocinon $10 \mathrm{u}$ iv sont administrées en alternance sur une période de $15 \mathrm{~min}$ pour produire des périodes de relaxation et de contraction propices à l'exploration utérine. Plusieurs tentatives pour extraire

\section{Key words}

ANAESTHESIA: obstetric, epidural;

UTERUS: oxytocics, nitroglycerin.

From the Department of Anaesthesia, Mount Sinai Hospital, University of Toronto, 600 University Avenue, Toronto, Ontario M5G 1 X5.

Address correspondence to: Dr. Andrew S.H. Chan, Department of Anaesthesia, The Toronto Hospital, Western Division, 399 Bathurst Street, Toronto, Ontario M5T 2S8. Accepted for publication 9th December, 1994. le placenta échouent et un diagnostic de placenta accreta est porté. Cette association de drogues ne produit pas d'effets secondaires majeurs à l'exception diune baisse transitoire de la pression artérielle après la NTG qui répond à l'éphédrine 10-15 $m g$ iv. On croit que le changement rapide de tonus utérin est dû en partie à la courte durée d'action de la NTG et du SYN, mais aussi à l'antagonisme physiologique présent entre les deux drogues. Le mécanisme de cette interaction pourrait s'expliquer par la mobilisation du calcium et la phosphorylation de la chaîne légère de myosine. Nous concluons que la NTG et le SYN peuvent être utilisés pour produire des courtes périodes alternantes de relaxation et de contraction utérines rapidement et de façon constante avec peu d'effets prolongés pour chacun des produits.

Induced uterine relaxation is occasionally required to facilitate intrauterine manoeuvres in certain obstetrical complications. Several recent reports described the use of $i v$ nitroglycerin (NTG) as a safer alternative than deep anaesthesia with a volatile agent or inhalation of amyl nitrite to produce uterine relaxation. Initial studies ${ }^{1,2} \mathrm{em}-$ ployed NTG 50-500 $\mu \mathrm{g} \dot{\boldsymbol{N}}$ to achieve tocolysis for removal of retained placenta in $>30$ patients. Subsequently, other authors reported the successful use of NTG $1 \mathrm{mg} \dot{v}$ in delivering the after-coming head in a difficult breech extraction, ${ }^{3}$ and NTG $100 \mu \mathrm{g} i v$ to relax an otherwise tightly contracted uterus during a Caesarean twin delivery. ${ }^{4}$ More recently, intrapartum external version of a second twin was facilitated by the use of NTG $50 \mu \mathrm{g} i{ }^{5}$ We describe a patient in whom repeated use of alternating doses of NTG and syntocinon (SYN) $i v$ produced periods of uterine relaxation and contraction for the attempted removal of a placenta accreta.

\section{Case report}

A 32-yr-old woman presented with retained placenta 40 min after spontaneous vaginal delivery at 34 wk gestation. Her history was unremarkable except for multiple missed abortions requiring evacuation of the uterus. An infusion 
of SYN $20 \mathrm{U} \cdot \mathrm{L}^{-1}$ had been started after delivery and the uterus was well contracted. After preloading with 1 $\mathrm{L}$ of balanced salt solution $i$, lumbar epidural anaesthesia was administered with $12 \mathrm{ml}, 2.2 \%$ carbonated lignocaine in divided doses to reach a sensory level of $T_{10}$. Systolic BP remained steady at $110-120 \mathrm{mmHg}$, and the SYN infusion was stopped. Manual removal of the placenta (MROP) was attempted but yielded only a small piece of placental tissue. Syntocinon $10 \mathrm{U} i v$ was given to help contract the uterus, but the placenta failed to separate. Five minutes later, the obstetrician requested induced uterine relaxation. Nitroglycerin $250 \mu \mathrm{g} i v$ produced moderate relaxation after two minutes. A second dose of $250 \mu \mathrm{g} i \mathrm{v}$ was given with resultant good relaxation. The MROP was again unsuccessful. A further bolus of syntocinon $10 \mathrm{U} i v$ was given to reduce bleeding with minimal side effects from the patient. One minute later, another obstetrician was consulted, who again requested uterine relaxation for re-exploration. A similar sequence of two doses of NTG $250 \mu \mathrm{g} i \mathrm{v}$ produced adequate relaxation. In both instances, a transient decrease of systolic BP to $85-90 \mathrm{mmHg}$ responded well to ephedrine $10-15$ mg $i v$. The placenta was felt to be extremely adherent to the uterine wall and a diagnosis of placenta accreta was made. Further intrauterine manipulation was abandoned to avoid uterine perforation. Syntocinon infusion was restarted and uterine tone was assessed as good. Blood loss was not excessive. The umbilical cord was cut just inside the cervix to allow spontaneous regression of the placenta. The patient was reassured and her recovery was uneventful. A follow-up abdominal ultrasound two weeks later showed a $11 \times 10 \times 7 \mathrm{~cm}$ placenta still confluent with the uterine fundus. Coagulation studies were normal up to the day she was discharged (day 21).

\section{Discussion}

Nitroglycerin has been demonstrated recently to provide life-saving uterine relaxation for difficult breech extraction $^{3}$ and twin delivery ${ }^{4}$ during Caesarean delivery. Its role in facilitating intrapartum external version of the second twin ${ }^{5}$ and allowing manual removal of retained placenta without resorting to general anaesthesia has also been well documented. ${ }^{1,2}$ This report is the first in English literature to describe the combination of NTG and SYN in the management of a retained placenta. It also demonstrated that these drugs can be administered to produce alternating uterine relaxation and contraction rapidly when required, but without sustained effects from either agent.

The diagnosis of placenta accreta in this patient was based clinically on the presence of an adherent placenta and the past history of multiple uterine evacuations. There was no pathological evidence to indicate how deeply the placental villi penetrated the implantation site. In about one-third of patients with placental accreta there is co-existing placental previa. These patients often present as severe postpartum haemorrhage neccessitating emergency hysterectomy, in which case adequate intravenous access and volume replacement is the mainstay of anaesthetic management. ${ }^{6} \mathrm{~A}$ few patients with placenta accreta may be managed conservatively, particularly in the low parity group. There were reports of such women conceiving again, but with a higher recurrence rate of adherent placenta in subsequent pregnancies. Our patient was not bleeding excessively and the placenta was found to be high up in the fundus. It was felt that removal of as much placental tissue as possible should be attempted.

The situation created an opportunity where the use of repeated, alternating doses of NTG and SYN in quick succession produced the desired uterine relaxation and contraction to facilitate uterine exploration in a controlled manner. Other situations where this approach may be useful are the salvage of the second twin in undiagnosed multiple pregnancies or facilitation of intrapartum external version, especially when oxytocics have been used. In our patient, such rapid changes of uterine tone occurred primarily because both NTG and SYN are shortacting drugs which last only minutes after a bolus dose. The short time lapse between the administration of NTG and SYN in this patient was probably sufficient for one drug to wear off partially and the other to exert its clinical effect. Secondly, NTG and SYN have opposite effects on uterine smooth muscle. Amyl nitrite, with an action similar to NTG, has been shown to be effective in attenuating oxytocin-induced uterine contractions, while producing negligible effect on spontaneous contractions. ${ }^{7}$ Whether any direct pharmacological interactions exist between NTG and SYN remain unclear.

Nitroglycerin and amyl nitrite have long been used to produce smooth muscle relaxation. It was only recently that such action was demonstrated to result from the formation of the reactive free radical nitric oxide. ${ }^{8}$ This in turn activates guanylate cyclase, leading to the intracellular accumulation of cyclic $3^{\prime} 5^{\prime}$ guanosine monophosphate (cGMP) and a possible decrease of intracellular calcium $\left(\left[\mathrm{Ca}^{++}\right]_{\mathrm{i}}\right)$. A cGMP-dependent protein kinase is activated which results in dephosphorylation of myosin light chains (MLC) and relaxation, ${ }^{9,10}$ While the actions of organic nitrates and nitrites are being revealed, the mechanism of receptor binding and the molecular site of action of oxytocin is less well understood.

Oxytocin increases the frequency and force of the contractile activity of uterine smooth muscle. ${ }^{11}$ In high concentrations, oxytocin causes sustained elevation of the resting membrane potential. This effect is oestrogendependent, explaining the heightened responsiveness of 
the uterus to oxytocics in late pregnancy. On the molecular level, early evidence indicated that oxytocin contracts term human uterus by an action on a high-affinity $\mathrm{Ca}^{++}$ATPase, probably inhibiting $\mathrm{Ca}^{++}$extrusion and leading to $\left(\left[\mathrm{Ca}^{++}\right]_{i}\right)$ accumulation. ${ }^{12}$ Other studies done in pregnant human myometrium in the presence of diltiazem have shown that oxytocin could cause transient and sustained uterine contractions in the absence of extracellular calcium $\left(\left[\mathrm{Ca}^{++}\right]_{\mathrm{ex}}\right)$, suggesting the release of $\mathrm{Ca}^{++}$from intracellular sites. ${ }^{13}$ Direct measurement of free $\left[\mathrm{Ca}^{++}\right]_{\mathrm{i}}$ in rat ${ }^{14}$ and human ${ }^{15}$ myometrial cells confirmed that up to $55-70 \%$ of the induced increase in $\left[\mathrm{Ca}^{++}\right]_{\mathrm{i}}$ depends on $\left[\mathrm{Ca}^{++}\right]_{\mathrm{ex}}$, with the rest probably mobilized from microsomes as a result of the production of the second messenger, inositol triphosphate ( $\left.\mathrm{IP}_{3}\right)$. All this, however, fails to explain the recent report in rats that oxytocin induces uterine smooth muscle contraction not only by MLC phosphorylation in a $\mathrm{Ca}^{++}$-rich medium, but also by another mechanism distinct from MLC phosphorylation in a $\mathrm{Ca}^{++}$-independent environment. ${ }^{16}$ Other protein kinases than MLC kinases, and cytoskeletal elements might be involved in $\mathrm{Ca}^{++}$-free contraction. ${ }^{17}$ It is thus speculated that NTG and SYN interact only partially in the control of uterine muscle tone, probably at the $\left[\mathrm{Ca}^{++}\right]_{i}-\mathrm{MLC}$ phosphorylation level. The presence of such antagonism of NTG by SYN in our patient may explain the higher NTG requirement $(500 \mu \mathrm{g} \dot{N}$ total) than previously reported. ${ }^{2}$ In the absence of a controlled study defining the optimal dosage of iv NTG for uterine relaxation, our regimen of titrating $250 \mu \mathrm{g} \dot{N}$ boluses has proved to be a practical compromise between the 500 $\mu \mathrm{g}$ used by Peng ${ }^{1}$ and the $50-100 \mu \mathrm{g}$ favoured by DeSimone, ${ }^{2}$ with respect to haemodynamic stability and tocolytic efficacy.

In conclusion, NTG and SYN can be used to produce alternating periods of uterine relaxation and contraction rapidly and consistently with little sustained effects from either agents because of their short durations of action and their mutual physiological antagonism. This combination provides optimal conditions for controlled exploration of the uterine cavity to remove a retained placenta, and may be useful for twin extraction in undiagnosed multiple pregnancies or for intrapartum external version. However, this technique should not be used in hypovolaemic patients or in patients with severe postpartum haemorrhage secondary to a retained placenta, when emergency hysterectomy may be the treatment of choice.

\section{References}

1 Peng AT, Gorman RS, Shulman DM, DeMarchis E, Nyunt $K$, Blancato $L S$. Intravenous nitroglycerin for uterine relaxation in the postpartum patient with retained placenta (Letter). Anesthesiology 1989; 71: 172-3.
2 Desimone $C A$, Norris $M C$, Leighton $B L$. Intravenous nitroglycerin aids manual extraction of a retained placenta (Letter). Anesthesiology 1990; 73: 787.

3 Rolbin SH, Hew EM, Bernstein A. Uterine relaxation can be life saving (Letter). Can J Anaesth 1991; 38: 939-40.

4 Mayer DC, Weeks SK. Antepartum uterine relaxation with nitroglycerin at Caesarean delivery. Can J Anaesth 1992; 39: 166-9.

5 Abouleish AE, Corn $S B$. Intravenous nitroglycerin for intrapartum external version of the second twin. Anesth Analg 1994; 78: 808-9.

6 Cunningham FG, MacDonald PC, Gant NF. William's Obstetrics, 18th ed. Norwalk, CT: Appleton \& Lange 1989: 415-24.

7 Kumar $D$, Zourias $P$, Barnes $A$. In vivo effect of amyl nitrite on human pregnant uterine contractility. Am J Obstet Gynecol 1965; 91: 1066-8.

8 Ignarro $L J$. Biological actions and properties of endothelium-derived nitric oxide formed and released from artery and vein. Circ Res 1989; 65: 1-21.

9 Kobayashi S, Kanaide H, Nakamura $M$. Cytosolic-free calcium transients in cultured vascular smooth muscle cells: microfluorometric measurements. Science 1985; 229: 553-6.

10 Murad F. Cyclic guanosine monophosphate as a mediator of vasodilation. J Clin Invest 1986; 78: 1-5.

11 Rall TW. Oxytocin, prostaglandins, ergot alkaloids, and other drugs; tocolytic agents. In: Gillman AG, Rall TW, Nies AS, Taylor P (Eds.). Goodman \& Gilman's The Pharmacological Basis of Therapeutics, 8th edn. New York: Pergamon Press. 1993: 933-53.

12 Popescu LM, Nutu O, Panoiu C. Oxytocin contracts the human uterus at term by inhibiting the myometrial $\mathrm{Ca}^{2+}$. extrusion pump. Biosci Rep 1985; 5: 21-8.

13 Kawarabayashi T, Kishikawa $T$, Sugimori $H$. Effect of oxytocin on spontaneous electrical and mechanical activities in pregnant human myometrium. Am J Obstet Gynecol 1986; 155: 671-6.

14 Anwer $K$, Sanborn $B M$. Changes in intracellular free calcium in isolated myometrial cells: role of extracellular and intracellular calcium and possible involvement of guanine nucleotide-sensitive proteins. Endocrinology 1989; 124: 17-23.

15 Tasaka K, Masumoto $N$, Miyake A, Tanizawa $O$. Direct measurement of intracellular free calcium in cultured human puerperal myometrial cells stimulated by oxytocin: effects of extracellular calcium and calcium channel blockers. Obstet Gynecol 1991; 77: 101-6.

16 Oishi K, Takano-Ohmuro H, Minakawa-Matsuo N, et al. Oxytocin contracts rat uterine smooth muscle in $\mathrm{Ca}^{2+}$-free medium without any phosphorylation of myosin light chain. Biochem Biophys Res Commun 1991; 176: 122-8.

17 Matsuo K, Gokita T, Karibe H, Uchida $M K$. Ca ${ }^{2+}$. independent contraction of uterine smooth muscle. Biochem Biophys Res Commun 1989; 165: 722-7. 